\title{
Studies on the rheological properties of aluminium oxihydroxide (boehmite) colloidal suspension
}

\begin{abstract}
This paper presents both experimental and theoretical aspects of the rheological properties and gelling behavior of boehmite suspensions over a range of $\mathrm{pH}$, temperature and concentration. Boehmite solï gel behaved as a non-Newtonian shear thinning fluid with the increase in consistency index $\mathrm{k}$ at lower $\mathrm{pH}$. The flow behavior index (n) representing the relative degree of shear thinning was influenced by $\mathrm{pH}$. The power law theory was used to explain the $\mathrm{k}$ and $\mathrm{n}$ for gelling behavior and the limit of pseudoplasticity of the boehmite suspensions. It was also found that the variation of activation energy with $\mathrm{pH}$ had an appreciable effect on the viscosity of the suspensions. Further it was observed that the density of the suspensions was strongly $\mathrm{pH}$-dependent, with a maximum density at $\mathrm{pH} 1$. Hence, it can be concluded that the rheological properties of colloidal aluminium oxihydroxide (boehmite) suspensions are predominantly affected by the physico-chemical parameters.
\end{abstract}

Keyword: Boehmite; Rheology; Solï gel; Non-Newtonian; Flow behavior index 